\title{
(IM)PURO PANERO
}

Túa BLESA, ed.: Leopoldo María Panero, Traducciones/Perversiones. Madrid, Visor, 2011, 352 pp.

rimero fue la Poesía completa 1970-2000, que pronto conocerá una segunda edición, después los Cuentos completos y, ahora, estas Traducciones/ Perversiones, un volumen que reúne todas las traducciones poéticas publicadas por Leopoldo María Panero. Así pues, con esta edición Túa Blesa, autor de numerosos estudios sobre el poeta y de una monografía ya clásica, Leopoldo María Panero, el último poeta, culmina -o casi- su labor de edición y análisis de la obra paneriana.

En el presente volumen, aparte de su trabajo como editor, en la mejor tradición filológica de cuidado y erudición provechosa, Blesa incluye un brillante estudio introductorio titulado "Teoría y práctica de la traducción como perversión" que resulta imprescindible para calibrar el alcance de la radical propuesta literaria de Panero en sus perversiones poéticas traductoras. Ya al principio nos advierte Blesa que las reflexiones de Panero sobre la traducción en diversos prólogos a sus traducciones suponen «una enorme distancia con el pensamiento general, o tradicional, sobre esta cuestión, como enorme es la distancia que media entre la práctica del Panero traductor y las más habituales» (p. 9). Además, algunas de las traducciones poéticas del autor han aparecido previamente en sus libros de poesía, de manera que «la diferencia entre escritura propia y traducción está desvanecida en dicho corpus» (p. 12). En este sentido también es especialmente significativa, como apunta Blesa, la elección de varios de los autores traducidos: por un lado, la constante presencia del mundo de la infancia, una infancia, además, que se presenta como perversión, cruel e inocente, de las crueles normas del mundo adulto, así los limericks del Nonsense Omnibus de Edward Lear o su A Nonsense Alphabet y The Hunting of the Snark de Lewis Carroll; y, por el otro, la de la literatura 
de terror, como es el caso de "Horrors" o "The Three Voices" de este último, o de "Childe Roland to the Dark Tower Came" de Robert Browning. Al respecto, Blesa cita estas palabras de Panero en su prólogo a su traducción de Peter Pan: «existen, creo -escribe-, dos antecedentes claros de la literatura moderna o de vanguardia: éstos son la literatura de terror y la literatura infantil» (p. 11). El resto de poemas y autores traducidos, como apuntábamos antes, mantienen también, como demuestra Blesa, una estrecha relación con la poesía de Panero, en donde además aparecen mencionados y/o citados: John Clare, Tristan Corbière, Georges Bataille, Catulo, "Farai un vers de dreit nien" de Guilhem de Peitieu - «la palabra en cuanto hueco, es, por otra parte, un tema muy característico de la poesía paneresca» (p. 13) ${ }^{1}-$ e, incluso, la canción "Jumpin' Jack Falsh" de los Rolling Stones.

En cuanto a la concepción de la traducción que tiene Panero, Blesa destaca "Lo que por fin dijo Benjamin”, prólogo del autor a El ómnibus, sin sentido de Lear. En él leemos, de la mano de Blesa, esta declaración benjaminiana de principios, clave en la poética traductora paneriana: «Que a la traducción cumple desarrollar -o superar- el original, y no "trasladarlo", como otro mueble cualquiera, de esta habitación a otra» (p. 17). Y en la línea de la personal lectura que hace Panero del magnífico y enigmático texto benjaminiano "La tarea del traductor", Blesa nos indica que el poeta, al traducir, suele leer, «más que en el texto, en los interlineados de los versos» (p. 19), lugar que, como indicaba Benjamin, citado por Blesa en nota al pie, había de ser el de la mejor traducción imaginable: «la versión interlineal de los textos sagrados es la imagen primigenia o ideal de toda traducción» (ibídem). Así, la tarea «de desarrollar -o superar- el original» no queda en Panero en una simple declaración de intenciones, sino que «en sus traducciones se llevará a cabo con todo rigor e ímpetu» (p. 18), hasta el punto de que «las traducciones panerescas son, en lo que sería el aspecto meramente cuantitativo, operaciones que responden a la clave retórica de la amplificatio» (p. 19). Veremos más abajo un ejemplo claro y significativo de estas palabras. Por ahora, sirva este otro de su traducción del "Preface" a The Hunting of the Snark, en que Blesa destaca en cursiva la interpolación que el traductor Panero se permite, y que acaba así: «Porque traducir es pervertir, es, de algún modo, crear monstruos» (p. 20). En la página siguiente, Blesa incluye un matiz fundamental a cuanto se viene diciendo: «la alteración textual es marca distintiva en la tarea de este traductor, una alteración [...] inherente a todo acto de traducción [...] aunque aquí ese ejercicio tiene como resultado una alteridad más aparente, radical» (p. 21, la cursiva, ahora, es nuestra). Es decir, que lo inherente a la traducción, a esa tarea que Benjamin llamaba Aufgabe -palabra que como enfatizaba Paul de Man en su ensayo sobre el texto benjaminiano significa tarea

\footnotetext{
${ }^{1}$ Sobre este asunto los lectores pueden consultar, con asombro y aprovechamiento, Logofagias (los trazos del silencio) de Túa Blesa.
} 
pero también abandono, rendición-, es una alteración textual inconcebible, una mutación fracasada: la repetición del acto mismo del original, la misma escritura, pero con otras palabras. O como dice el propio poeta en su traducción del citado "Preface", «volver a pronunciar, a escribir, digamos lo impronunciable, lo garantizado como inefable» (p. 280). Por eso Panero se plantea la traducción, por un lado, como una perversión, o sea, como un goce perverso, un abandono de sí mismo, pues la «sitúa en una dimensión místico-alquímica, libidinosa, trabajo de escritura del goce y para el goce, que habrá de ser liberador» (p. 29) ${ }^{2}$; y, por otro, como una labor de espeleología del sentido, mediante la metáfora de la grieta: cada texto, para cada lector, presenta una grieta por la que internarse para su lectura o traducción, de modo que habrá tantas interpretaciones y traducciones posibles como lectores/traductores capaces de hallar una grieta por donde internarse en busca del sentido. Así, en su texto "Sobre la traducción", «Panero apuntaba oportunamente cómo el significado del latín explicare es 'desplegar' [...] lo cual venía a reiterar la idea de la traducción como desarrollo -o superación- del original, cuyos sentidos latentes se harían manifiestos en la traducción» (p. 27). Queda pues abolida, como indica Blesa en este párrafo, la idea de texto como monumento inalterable y definitivo:

[...] el texto del que Leopoldo María Panero habla tiene como condición necesaria el inacabamiento, un inacabamiento que salta a la vista gracias a la lectura y a la traducción, perversión, esa forma de lectura que da en escritura. Por ese inacabamiento el texto no puede ser ya pensado como conjunto cerrado, homogéneo, sino agrietado, ya no como tejido, sino deshilachado, en proceso de tejerse y destejerse, imagen de Penélope a la espera de que cada lectura, cada traducción, perciba un cierto instante de tal proceso, siendo entonces el texto un fluido o, como dice Panero tomando la expresión de Maurice Blanchot, la ausencia de texto, que sería aquí, cuando menos, la ausencia de texto en cuanto tejido (p. 31).

Dicho de otra forma, la traducción, como decía Benjamin, eleva el original a una nueva vida, «a un lugar que sobrepasa al original, por lo que su estatus será el de escritura hiperliteraria» (p. 27), matiza Blesa refiriéndose a Panero. Porque si la propuesta teórica y práctica del Panero traductor resulta tan radical como lo son su escritura poética o en prosa es porque entra en conflicto con algo que suele darse por descontado, pero que la práctica literaria cuestiona a cada paso: el principio de autoridad. Blesa lo sintetiza con una definición de traducción absolutamente perversa y paradójica, pero más que certera: «escritura que, siendo reescritura, produce un texto original»-algo que en las adaptaciones cinematográficas, con el cambio de código semiótico que implican, todos tenemos muy claro y hemos aceptado-, porque eso supone «hacer de la segunda escritura, la cita, la traducción y el plagio, la expresión más

\footnotetext{
${ }^{2}$ Sobre el sentido de ese goce literario en libertad léase, para experimentarlo, el libro de Túa Blesa Scriptor Ludens (Ensayo sobre la poesía de Ignacio Prat), poeta compañero de generación de Panero y no menos maldito.
} 
literaria de lo literario» (p. 38). Y sí, eso nunca es tan verdad, o casi nunca, como en los textos traducidos por Panero, pero Blesa nos hace ver además que eso siempre es verdad en cualquier texto, que por definición será (re)escritura, (re)inscripción de una lejanía y una tradición, de una distancia hecha de alteridad linguiística, geográfica y/o temporal, en el aquí y ahora.

Encontramos por tanto en última instancia, en la poética y la práctica traductora de Panero, un ataque frontal contra la idea de que el conocimiento de la realidad es independiente del medio lingüístico que nos permite explica(/á)r(nos)la; contra la traducción entendida como un simple cambio de lengua, de un significante por otro, en que el significado -y el sentido- quedan incólumes, permanecen inalterados cual sofá que cambia de casa, en el peor de los casos, con un arañazo o un leve desgarro, pero nunca convertido en un sofá-cama, en una mesa o en una taza de váter... Un ataque frontal, decíamos, pero también paradójico, ya que el traductor Panero no es un versioneador, un merodeador de la traducción, por muy perversor literario o antitraductor que se diga a sí mismo -y lo es-, sino un traductor en el sentido más profundo de la palabra: alguien que, como todo escritor, lleva algo a través de un medio que es algo mismo, a través de las lenguas, las épocas y los textos propios y ajenos; y si bien ese algo -llamémosle contenido o vivencias o como se quiera- queda inevitablemente transformado con cada traslado, indefectiblemente amalgamado con el medio, al final del viaje y de la metamorfosis todavía resulta reconocible como lo mismo, imposible, monstruosa y perversamente igual, siendo como es otro también.

Ahora, para acabar, un par de ejemplos de lo dicho. El primero, una breve demostración de que el desarrollo y superación que supone la traducción/perversión no es nunca gratuita, sino entretejida o espeleológica: donde el duque de Aquitania Guilhem de Peitieu, famoso en su corte por su histrionismo, procacidad, ingenio y éxito con las damas, escribe «quan no la vei, be m'en deport», el legendario y transgresor poeta maldito Leopoldo María Panero traduce «si no la veo, me la suda».

El segundo ejemplo, demostración de lo mismo a mayor escala y calado, son unos versos de la traducción/perversión de un soneto de Bataille que Panero titula, significativamente, "Mutación de Bataille" y que se incluye en la no menos significativa sección "Palimpsestos". Se trata, como informa Blesa, de un poema excluido por el autor -¿cabe más marginalidad?- de su poemario L'Archangélique. He aquí la primera estrofa pervertida: 


\begin{abstract}
Yo soñé con tocar la tristeza viscosa del mundo en el desencantado borde de una ciénaga absurda yo soñé un agua turbia donde reencontraría el camino perdido de tu ano profundo;
\end{abstract}

Como en una preparación del cuarto verso, el adjetivo del primero es puro desarrollo de Panero, que traduce en el segundo étrange por absurda y que acaba convirtiendo en el último que acabamos de leer «les chemins égarés de ta bouche profonde». A continuación, el segundo cuarteto de Bataille se transforma en su mutación paneriana en una estrofa de siete versos, donde la interpolación, que cito, sigue explorando el campo semántico abierto por el citado orificio: «salvaje como el viento, como el negro agujero / de tu cuerpo que me hace soñar».

Tanta arbitrariedad, y tan transgresora, queda explicada, o al menos apuntada -pues, como hemos visto antes, el título de la sección donde se incluye el poema invita a leer entre líneas, debajo o más allá de la escritura aparente-, en el desarrollo aún más explícito que, siguiendo la lógica anal de los versos cuarto, séptimo y octavo, recibe el segundo terceto del soneto de Bataille, que Panero multiplica por cuatro -resalto en cursiva las interpolaciones más significativas-:

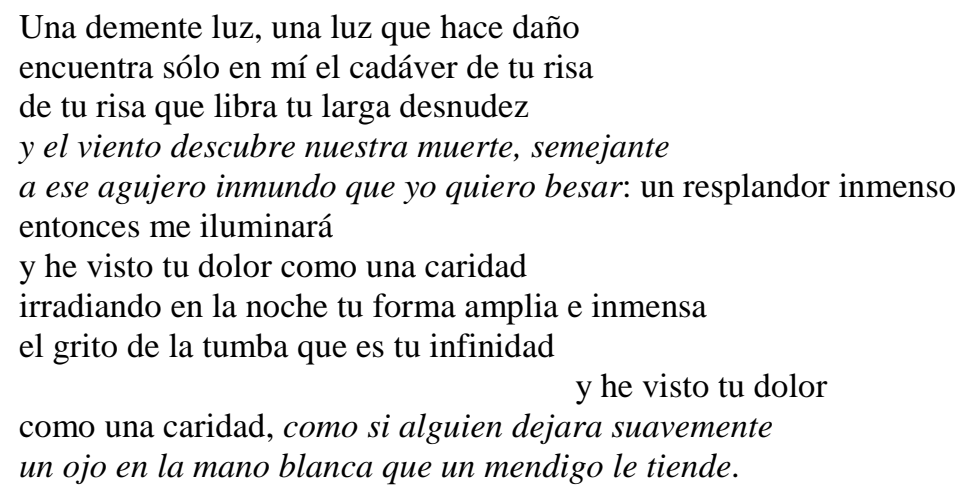

Ese ojo exorbitado en una mano blanca -si bien no la de un mendigo, lo que aporta un incremento marginal- podría remitir, chez Bataille, al macabro y sacrílego final de Historia del ojo, publicada el mismo año que L'Archangélique, y, en concreto, a los juegos de Simone con el globo ocular del cura don Aminado. Además, al principio de esa novela, como al principio del poema, hay un desplazamiento léxico-fisiológico. O mejor dicho, lo que en la novela es un pequeño desplazamiento que en ocasiones crea ambigüedad: «Todavía no había podido verla hasta el culo (ese nombre que empleaba con Simone me parecía el más bonito de los nombres del sexo)» (p. 51, trad. de Antonio Escohotado), dice el perverso narrador, que nos cuenta sus crueles e infantiles aventuras sexuales de adolescencia junto a la aún más perversa Simone; ese desplazamiento de unos pocos centímetros, en "Mutación de Bataille", más que una simple mutación, ha 
devenido una inversión de cabo a rabo ${ }^{3}$ : el final del tracto digestivo ocupando el lugar de su principio. Así pues, con su ano por boca -no sólo el orificio no reproductivo, evacuatorio, nefando, sino éste en lugar de su opuesto más alejado y contrario, el de la entrada de los alimentos, el de la palabra, el sonido articulado-, Panero, desde la obra misma de Bataille, habría desarrollado y superado -o pervertido-, habría ido más allá del poema de Bataille y también de aquel inicio de Historia del ojo, como parece apuntar al final de su traducción con una interpolación nada gratuita, ya que nos remitiría al sacrílego final de la novela.

Podemos afirmar, entonces, que con su incursión por esa grieta de carne llamada bouche que le ha transportado a una órbita vacía, grieta también de carne viva, el heterodoxo Panero habría analizado, desde el interior de Bataille, el soneto de Bataille... Porque con esa palabra heterodoxa, tan lejos de la opinión y el decir comunes, es con la que mejor se pueden articular las verdades incómodas, escandalosas, obscenas. Y la verdad que desvelan las perversas traducciones de Panero es que la traducción, toda traducción, y con ella toda escritura, como nos recuerda y explica Túa Blesa en su estudio introductorio, es un intento vano, e inevitable, de reconstrucción del sentido primigenio, de aquella «reine Sprache», lenguaje puro, de que hablaba Benjamin en "La tarea del traductor". Panero, y con él Blesa, nos hacen insoslayable que tal cosa como un lenguaje puro no existe y que, no obstante, detrás o debajo de las perversiones lingüísticas de este libro se esconde el acceso a la sabiduría que apuntaba Blake, la de aquellos que por la vía del exceso y la transgresión -«ya sea por la locura, por el alcohol, por la droga, ya sea por la mera palabra, o más bien por la extrapalabra», escribe el poeta (p. 152)- no han renunciado, como Panero, cual devoto de $\mathrm{Pan}^{4}$, a la melancolía pura del paraíso perdido -llámese infancia o principio del goce absoluto-, ese palacio que nunca hemos pisado ni pisaremos si no es fuera del tiempo. Panero, pues, en estado (im)puro.

\section{Salvador COMPANY GIMENO}

UCV San Vicente Mártir

\footnotetext{
${ }^{3}$ Conviene, quizá, recordar en este punto aquella constante e implacable inversión, no sólo de las trayectorias y gustos de los personajes sino también de los valores establecidos, de que habla Barthes en "Une idée de recherche" para describir el funcionamiento rotatorio de la novela de Proust.

${ }^{4}$ Curiosamente, existe una tradición mitológica que hace de Pan el hijo de todos los amantes simultáneos que habría tenido una Penélope, la incesante tejedora-destejedora, menos ejemplar que la del texto homérico.
} 